\title{
¿QUÉ ENSENAAR Y PARA QUÉ ENSEÑAR FILOSOFÍA?
}

Vicente Sánchez Álvarez

\section{Introducción}

El presente artículo, “Qué enseñar y para qué enseñar filosofía?", tiene un doble propósito. Por un lado, pretende analizar aquello que se puede enseñar en la actividad que se ha dado en llamar 'Filosofía'. Esto es, se tratarían de buscar las condiciones trascendentales de la enseñanza de la filosofía; tomando aquí trascendental en un sentido próximo al que emplea Kant en su teoría del conocimiento: en nuestro caso, como condiciones de posibilidad de la enseñanza de la filosofía.

Por otro lado, y no desde luego menos importante, se plantea una reflexión acerca del sentido de la filosofía hoy día, ¿para qué la filosofía? Es decir, una reflexión sobre determinados planteamientos que apuntan hacia el final de la filosofía.

\footnotetext{
* Doctor en Filosofía por la Universidad Complutense de Madrid. Se doctoró en 1998, defendiendo la tesis Origen y sentido del nihilismo en la filosofía de Nietzsche. Ha colaborado, de forma esporádica, con la revista, Anales del seminario de metafísica de la Universidad Complutense de Madrid. Actualmente es profesor en el Instituto de Enseñanza Secundaria, Peñalara, de la localidad de San Ildefonso en Segovia (España).
} 


\section{1. ¿Qué enseñar en Filosofía?}

De entrada, la pregunta que da título a este epígrafe puede resultar extraña, cuando no absurda: ¡Qué tontería! En Filosofía se enseña, se debe enseñar, un conocimiento concreto. Muy bien, pero, ¿qué tipo de conocimiento?, ¿acaso la Historia de la Filosofía es ese tipo de conocimiento? La historia de la filosofía, como su nombre lo indica, no es nada más que eso, historia: historia de los sistemas filosóficos y sus autores; historia de las ideas que han ido configurando las distintas etapas de la filosofía occidental $^{1}$, desde los griegos hasta nuestros días. Ahora bien, ¿estamos seguros de que la historia de algo pueda ser considerada, en sentido estricto, conocimiento acerca de ese algo?, ¿es el conocimiento filosófico solo eso?, es decir ¿historia? De momento dejemos estas preguntas aquí. Volveremos sobre ellas.

Ensayemos otra posible respuesta. El conocimiento filosófico es una propedéutica, una suerte de introducción al vasto campo del saber producto del esfuerzo intelectual humano. Este planteamiento parece un poco más sólido. Sin embargo, no deja de ser inquietante. ¿La razón de ello?: tenemos la impresión de que la filosofía se queda en el umbral del conocimiento; la vaga sensación de que ese saber propedéutico es poco importante en relación a lo que viene después.

Puestas así las cosas, deberíamos volver a preguntar: ¿qué se debe enseñar en Filosofía?, ¿la historia o la propedéutica?, ¿o las dos?; o, siendo más radicales, ninguna de las dos, porque el llamado saber filosófico se ha convertido en una arqueología, en una actividad donde los profesores de filosofía se limitan a desempolvar ante sus alumnos los escritos de los filósofos como si estuvieran realizando una 'exhumación' de ideas y conceptos vacíos, que ya no sirven para nada. 
Todo esto suena desolador. No obstante, más allá de la irritación y el dolor que pueda causar este planteamiento; más allá del orgullo herido, tendríamos que tener presente, si todavía queda en nosotros un impulso genuinamente filosófico (por paradójico que suene), que el análisis crítico de la realidad y el amor por la verdad, sea cual fuere, deben estar por encima de nuestros gustos y creencias. Si la filosofía ha sido algo a lo largo de su historia, no ha sido otra cosa nada más que el ejercicio del pensamiento libre, reflexivo, crítico y que busca la verdad. Sin estos valores, la filosofía se pervierte y carece de sentido. Se convierte en el opio del conocimiento. ¿Es la filosofía, debe ser la filosofía, ese opio que adormece la capacidad crítica de nuestros estudiantes, tanto en la enseñanza secundaria como en la Universidad?

En cualquier ámbito de la realidad, las posiciones extremas suelen conducir a un callejón sin salida. No se trata aquí, de rescatar la conocida teoría aristotélica acerca de la virtud como término medio entre dos extremos. Ahora bien, en pocas circunstancias de la vida, situarse en un extremo resulta razonable o clarificador. En el caso que nos ocupa, el supuesto conocimiento filosófico debe situarse, a nuestro juicio, entre la propedéutica y la historia. Es decir, debemos preparar a nuestros alumnos, primero, introduciéndolos en lo que ha significado históricamente la filosofía y sus diversas manifestaciones; y, después, en un segundo momento, pasar al análisis de las teorías y cuestiones verdaderamente filosóficas. Dando un paso hacia adelante deberíamos llevarlos, incluso, a tratar los planteamientos más relevantes, hoy día, que enlacen con la tradición filosófica.

Aquí surgen dificultades que se relacionan con los contenidos y con el nivel de profundidad. Hablando de los contenidos, una vez más, deberíamos preguntar, ¿qué enseñar en Filosofía?, ¿enseñar los pensamientos de los au- 
tores de manera cronológica?, o más bien organizar la filosofía en núcleos temáticos; por ejemplo, la naturaleza, la sociedad, la ética, la política, etcétera. Desde nuestro punto de vista, el problema del contenido, no solo es el primero que se plantea en la enseñanza de la filosofía, sino también el más complicado.

Nadie ignora que la civilización actual se caracteriza por un aumento vertiginoso del conocimiento en todos los ámbitos o esferas de la realidad. Hoy día resulta imposible concebir la imagen de un hombre o una mujer, ilustrado o ilustrada, al modo del Renacimiento. Es decir, como alguien que es capaz de dominar múltiples campos del saber. A duras penas, los especialistas de una materia, pueden estar al día de los avances que se producen en ella.

Se podría objetar, no obstante, que tampoco es tarea de la filosofía académica ${ }^{2}$ abordar aquello que en el resto de los saberes no se puede resolver. Es cierto, mas no es esa la cuestión. La cuestión es que si el saber avanza de la forma en que lo hace, entonces, los distintos planes de estudio $^{3}$, que deben determinar lo que han de aprender los alumnos, no solo tienen que estar actualizados de forma permanente sino que, a la fuerza, deberán filtrar el nivel de conocimientos para que los estudiantes puedan asimilar, en verdad, algo. En este contexto, podríamos preguntarnos, ¿deben estudiar filosofía nuestros alumnos, o bien dedicar su tiempo a otras materias?; y, en caso afirmativo, ¿qué tipo de filosofía?, ¿qué contenidos han de aprender? Pongamos por caso, ¿es mejor que estudien doctrinas de tipo metafísico, por ejemplo, que se planteen cuestiones acerca de la realidad de los conceptos universales?, ¿o más bien, deberían inclinarse hacia la filosofía de la ciencia y del lenguaje?

Es un problema serio. Pero no solo en la filosofía, también lo es en el campo del saber en general. Además, es una cuestión que, en su momento, quedó planteada, a 
comienzos del siglo pasado, en la sociología de Max Weber. Es cierto que este autor la centró en lo que denominó, proceso de racionalización occidental ${ }^{4}$, esto es, el proceso por el cual las diversas esferas de lo real son subsumidas bajo el férreo control de la razón. Esto trae consigo un desencantamiento de la realidad, que sería la consecuencia negativa de dicho proceso. Bajo el prisma del conocimiento, la racionalización provoca una sensación de hastío o cansancio ante la imposibilidad de poder abordar, en el trascurso de una vida humana, la ingente cantidad de datos; el enorme caudal que va adquiriendo el saber en general. Prestemos atención al siguiente fragmento, extraído de una de las obras de Weber:

\begin{abstract}
Abraham o cualquier campesino de los viejos tiempos moría "viejo y saciado de vivir" porque estaba dentro del círculo orgánico de la vida; porque, de acuerdo con su sentido inmanente, su vida le había ya dado al término de sus días cuanto la vida podía ofrecer; porque no quedaba ante él ningún enigma que quisiera descifrar y podía así sentirse "satisfecho". Por el contrario, un hombre civilizado, inmerso en un mundo que constantemente se enriquece con nuevos saberes, ideas y problemas, puede sentirse "cansado de vivir", pero no "saciado". Nunca habrá podido captar más que una porción mínima de lo que la vida del espíritu continuamente alumbra, que será, además, algo provisional, jamás definitivo (Weber, 1984: 201).
\end{abstract}

El hombre al que se refiere Weber en el texto citado, Abraham, moría viejo y, a la vez, "saciado de vivir". ¿Por qué?: porque la vida le había revelado todo cuanto se podía conocer; porque el ámbito del saber era lo suficientemente estrecho como para poder ser abordado en el discurrir de una vida humana. Hoy en día, tal cosa resulta imposible; y en el mejor de los casos, tras una vida dedicada al conocimiento y a la investigación, el sentimiento que nos domina 
es el de la frustración ante lo poco que hemos obtenido a pesar de tanto esfuerzo, la impotencia ante todo lo que nos queda aún por conocer. El saber, pues, se ha convertido en algo gigantesco, y la filosofía no parece haber encontrado su camino en medio de semejante selva de conocimientos.

A diferencia del saber de contenido científico, la filosofía no puede esperar demasiado, por no decir nada, del trabajo conjunto de sus diversos autores. Más aún, daría la sensación de que el conocimiento filosófico lo es, en la medida en que se convierte en algo puramente individual. Esto supone una desventaja desde la perspectiva de su eficacia. La dificultad radica, en ser capaz de transmitir y asegurar al mismo tiempo, el conocimiento de la tradición filosófica y la actualidad del denominado saber filosófico (dicho de otra forma, asegurarnos de que el saber filosófico no se limite a ser, tan sólo, un objeto de la curiosidad erudita y tenga una proyección real en el mundo actual).

¿Tiene hoy día fuerza la filosofía para realizar semejante tarea? ¿Somos capaces, los que nos dedicamos a la enseñanza de la misma, de llevar a nuestros alumnos a esos dos planos? De la respuesta afirmativa a estas preguntas dependerá, de alguna manera, ese saber que Gabriel Albiac, glosando a Platón, califica de "juego de la inteligencia":

El milagro de la filosofía está cifrado en la enigmática intemporalidad de sus enunciados. Y en lo inútil de ellos para cambiar nada. Ahora que su ciclo histórico de dos mil seiscientos años está a punto de cerrarse, como a punto de cerrarse está el invento de solo siete siglos al cual hemos seguido llamando Universidades; ahora, desde el raro privilegio de haber pertenecido a la última generación que académicamente se dedicó a esa tarea bella y vana, a ese bello y vano lujo del espíritu llamado filosofía, sé que fue tal inasible intemporalidad la que me llevó a abrazarme a un juego de inteligencia que -dice Platón 
al codificarlo en la luminosa Atenas- no lleva a ninguna parte, pero es hermoso (Albiac, 2009: 10).

Juego de la inteligencia, bella ilusión, porque, una vez que la filosofía abandona el terreno del pensar solitario; es decir, una vez que la filosofía desciende a las aulas para convertirse en un 'saber fijado' que pueda ser transmitido, aprendido y asumido por los alumnos, pierde, ipso facto, su fuerza crítica. Fijar la filosofía como un 'contenido enseñable', es obligarla a renunciar a lo mejor de sí misma, es despojarla de su sentido. Queramos o no, la filosofía jamás puede competir, como forma de conocimiento, con el conocimiento científico. Si la filosofía es un conocimiento, lo es de una manera tan especial que no se deja encasillar de la misma forma que cualquier otro conocimiento.

Muy a menudo, y no sin parte de razón, los alumnos que estudian filosofía, en cualquier nivel, se quejan de lo incomprensible de la misma. Así, la historia de la filosofía se presenta ante ellos como una singular aventura digna de visionarios en la que sus protagonistas, los filósofos, no hacen otra cosa nada más que disputar entre sí. El resultado de semejante disputa conduce a la exposición, por parte de cada autor, de una teoría, de una filosofía, opuesta y más extraña que la anterior. Algo parecido a lo que se acaba de señalar deja escrito Kant, pero, a propósito de la metafísica:

Por lo que toca a la unanimidad de lo que sus partidarios afirman, está aún tan lejos de ser un hecho, que más bien es un campo de batalla realmente destinado, al parecer, a ejercitar las fuerzas propias en un combate donde ninguno de los contendientes ha logrado jamás conquistar el más pequeño terreno ni fundar sobre su victoria una posición duradera (Kant, 1995: 19).

Los historiadores de la filosofía y los profesores de la materia, se esfuerzan por otorgar una estructura, un senti- 
do, a esa aventura del saber. Sin embargo, ni los temas ni los diversos propósitos de sus diferentes autores, contribuyen demasiado a disipar en los alumnos las dudas que suscitan semejantes planteamientos: ellos no ven ni el sentido de la filosofía, ni tampoco qué relación pueda existir entre aquélla y los problemas que se plantean en el mundo actual.

Llegados a este punto, se podría argumentar que lo que se ha expuesto hasta ahora resulta demasiado exagerado. Que, por ejemplo, cabe señalar conexiones entre los planteamientos y propuestas de ciertos filósofos y lo que sucede hoy día. Así, podría aducirse que la cuestión de la relación entre ética y política es algo que, más que nunca, está hoy en vigor. Siguiendo el hilo de esta argumentación cabría recurrir a textos de la República de Platón, o a ciertos fragmentos de la Política de Aristóteles. Por no hablar de la confrontación de Sócrates con los sofistas, con la dimensión ética de fondo, a la hora de tratar los fundamentos y la legitimidad del poder político. Otro tanto sucede si dirigimos la mirada hacia las relaciones entre la fe y la razón, fundamental en la filosofía medieval, que en nuestros tiempos ha vuelto a resurgir enfocada, ahora, como confrontación entre la ciencia y la religión.

Todo ello resulta cierto. Pero deberíamos proceder con cautela. Rescatar textos antiguos, por venerables que sean, nos impone la tarea, el deber, de releerlos y, si es posible, actualizarlos. La filosofía, en tanto actividad propia de seres humanos, limitados, propensos a los prejuicios $\mathrm{y}$ al error, no puede adquirir nunca la forma de una verdad absoluta (a pesar de que ciertos filósofos y corrientes filosóficas se hayan presentado como tal), una especie de dogma inconmovible. Situar en primer plano los escritos de los clásicos, presentarlos ante nuestros alumnos y el público en general, es una labor que solo se debería llevar a cabo, revestidos de una buena dosis de espíritu crítico y escepticismo ${ }^{5}$. Ninguna filosofía puede ser descontextuali- 
zada, ningún filósofo puede ser entendido como un oráculo para tiempos futuros: ni tan siquiera aquellos que, bien ellos mismos, o la tradición posterior, se han considerado o han sido considerados, como 'adelantados a su época'.

Lo expuesto anteriormente tendría que bastarnos para hacernos reflexionar acerca del delicado trabajo de interpretación de los textos filosóficos de cualquier época; sobre todo, cuando se trata de aclararlos y 'adaptarlos' al mundo actual. En realidad, y en muchas ocasiones, el pensamiento filosófico no nos permite sacar conclusiones nada más que de modo negativo; nos dice lo que no debemos pensar, los caminos que no debemos seguir, puesto que, las mismas experiencias filosóficas, ya nos han mostrado a dónde conducen: a un laberinto sin salida, o a una salida dramática, terrible, sin sentido.

Así pues, haríamos bien en no considerar el llamado conocimiento filosófico como un tipo de conocimiento progresivo, similar al conocimiento científico. Pero, en el supuesto de que todavía quisiésemos seguir insistiendo en hablar de cierto progreso en la filosofía, entonces, tal vez nos resultaría útil considerar que el saber filosófico progresa a modo de círculos concéntricos; tal y como sugiere Ortega y Gasset:

Los grandes problemas filosóficos requieren una táctica similar a la que los hebreos emplearon para tomar a Jericó y sus rosas íntimas: sin ataque directo, circulando en torno lentamente, apretando la curva cada vez más y manteniendo vivo en el aire son de trompetas dramáticas. En el asedio ideológico, la melodía dramática consiste en mantener despierta siempre la conciencia de los problemas, que son el drama ideal (Ortega y Gasset, 1972: 18).

El hilo argumental de nuestra exposición nos lleva de nuevo al terreno de las preguntas. He aquí el interrogante, ¿qué valor, pedagógico y no pedagógico, tiene 
para nosotros hoy la historia de la filosofía? Evidentemente, es bueno conocer los caminos que han recorrido los filósofos para que, al menos y como se mencionó anteriormente, no volvamos a tenerlos que recorrer y caer en los mismos errores. No obstante, el espíritu crítico no debería abandonarnos en ningún momento. Debemos estar en guardia frente al dogmatismo y los errores que se deslizan en los textos; ser más exigentes con las conclusiones a las que llegan; y plantear los puntos débiles de sus argumentaciones a la hora de analizar los fragmentos que han de ser explicados a los alumnos. Sin olvidar, por supuesto, el contexto histórico en el que surgen, la limitación del horizonte cultural en el que nacen, y los prejuicios que pueden encerrar.

Desde nuestro punto de vista, el mayor valor que posee la historia de la filosofía es el que se refiere a la invitación a la reflexión sobre lo que ha sido esta actividad. Hay que esforzarse por mostrar a nuestros alumnos, que el ejercicio crítico de la razón, que toda la energía racional desplegada y cristalizada en esa actividad llamada filosofía, no es otra cosa que el impulso que lleva al ser humano a buscar un sentido a su existencia. Ese ejercicio, ese noble esfuerzo, nos lleva a dar lo mejor de nosotros mismos: a ejercer la capacidad racional que nos aleja del ámbito material y nos abre a la trascendencia; religiosa o no, pero trascendencia a fin de cuentas.

Con respecto al nivel de profundidad, lo primero que hay que indicar es que, como no podía ser de otra manera, se relaciona con los contenidos. Una vez que se han determinado éstos, será menester empezar a trabajar aquélla. ¿En qué dirección? Eso va a depender de lo que se quiera lograr; pero, en principio, el nivel de profundidad ha de ser mayor en la enseñanza universitaria que en la secundaria. De todas formas, no debemos olvidar que la filosofía ya es, en sí misma, un saber complejo y abs- 
tracto, bastante alejado del sentido común y que exige un esfuerzo intelectual para acceder a sus contenidos. Además, tampoco se gana nada, desde el punto de vista pedagógico, cuando se simplifican de forma excesiva, o peor aún, se trivializan sus contenidos (reduciendo al mismo tiempo su nivel de profundidad).

Por otro lado, dadas las peculiares características del saber en la actualidad, su enorme desmesura y, por extraño que suene, su gran fragmentación; resulta que la única manera que tenemos de acceder a una visión global de los problemas que se plantean es acudiendo a la filosofía. Ella es el único cauce o camino lo suficientemente universal, abstracto y racional como para poder ofrecer una panorámica de conjunto y estar en condiciones de entender todo aquello que la ciencia, por su propia dinámica, no es capaz de captar.

Para concluir este primer epígrafe, ¿qué enseñar en filosofía? Por un lado, parte de esos contenidos que la tradición ha dado en llamar historia de la filosofía; centrándolos, en especial, en aquellos que se acerquen más a los problemas de nuestro tiempo. Por el otro, enseñar al alumno a pensar por sí mismo; a llevar a cabo el ejercicio crítico de la razón. Porque hoy día, quizás con mayor necesidad que en otros momentos de la historia, debemos volver a recordar aquí el conocido lema de la ilustración kantiana: ¡Sapere aude! Ten el valor de usar tu propio entendimiento ${ }^{6}$.

Finalizamos, retornando a lo ya expuesto en párrafos anteriores; esto es, sin un ejercicio libre, reflexivo, y crítico de la razón, que incluye la búsqueda de la verdad, no puede darse, no puede existir, un saber que merezca recibir el nombre de filosofía. 


\section{2. ¿Para qué enseñar filosofía?}

Siguiendo el itinerario marcado al comienzo del presente artículo, abordamos ahora la segunda cuestión, la que apunta al para qué enseñar filosofía.

Cualquiera que haya prestado atención a la exposición que se ha realizado hasta aquí podría interrogarse, con toda la razón, a propósito de la idoneidad del planteamiento del autor: es decir ¿̇hasta qué punto no están invertidas el orden de las cuestiones?, ¿no se debería haber tratado, en primer lugar, el para qué, en general, de la filosofía; antes de hacer frente al qué enseñar en filosofía?, ¿no resulta de sentido común suponer que si la filosofía no tiene ningún sentido, tampoco deba ser enseñada?, ¿no estaría el autor de este artículo procediendo de modo incoherente?

No debe caber ninguna duda de que el autor de este artículo, al plantear las cuestiones en ese orden, da por sentado tanto el valor y el sentido de la filosofía; así como la importancia de la enseñanza de la misma. A pesar de ello, no se trata aquí de una simple petición de principio; no se pretende, en modo alguno, dar por sentado lo que es menester demostrar. Si se dejó la cuestión del para qué de la filosofía en un segundo lugar, no se debe a su menor importancia o porque se quiera partir con ventaja: si se aborda en un segundo término, es decir, en la parte final de este artículo, es porque resulta fundamental y su interés va más allá de la cuestión de su enseñanza académica y su valor pedagógico. Porque, aunque conectados, los campos que se ocupan de la enseñanza de la filosofía y del sentido de la misma (entendiendo aquí la filosofía como una actividad que conduce a la exposición de un doctrina o sistema sobre la realidad), son completamente diferentes.

Así pues, no nos dejemos engañar: bajo el título del epígrafe, ¿para qué enseñar filosofía?, late una cuestión no académica, sino genuinamente reflexiva que podríamos 
plantear de la siguiente manera: ¿tiene algún sentido, en nuestra época, esa bella ilusión que hemos dado en llamar filosofía?, ¿hemos llegado -como afirmaba Heidegger-, al final de la filosofía?, ¿se ha cerrado el círculo histórico de la filosofía?

Que el ser humano ha filosofado, que ha hecho filosofía, es algo obvio. La filosofía, desde sus orígenes, se nos presenta como un quehacer relacionado con la razón, ¿por qué? Ya decía Ortega y Gasset que si el ser humano piensa en términos filosóficos es porque la filosofía es algo constitutivo del intelecto:

La filosofía no brota por razón de utilidad, pero tampoco por sinrazón de capricho. Es constitutivamente necesaria al intelecto. ¿Por qué? Su nota radical era buscar todo como tal todo, capturar el Universo, cazar el Unicornio. Más, ¿por qué ese afán? ¿Por qué no contentarnos con lo que sin filosofar hallamos en el mundo, con lo que ya es y está ahí patente ante nosotros? Por esta sencilla razón: todo lo que es y está ahí , cuanto nos es dado, presente, patente, es por su esencia, mero trozo, pedazo, fragmento, muñón, Y no podemos verlo sin prever y echar de menos la porción que falta (Ortega y Gasset, 1972: 99).

La filosofía ha intentado, desde sus inicios, situar al hombre en el $\operatorname{cosmos}^{7}$, dar un sentido a su vida. Cierto es que la filosofía no ha sido la única tabla de salvación (si se nos permite esta expresión), del sentido y los valores. También las distintas confesiones religiosas han desempeñado un preponderante papel en esa dirección. Incluso, en la actualidad, el conocimiento científico nos ofrece una visión científica de la realidad que para muchos puede sustituir (y para otros sustituye, perfectamente), a las 'antiguas' explicaciones filosóficas y a las creencias religiosas.

Frente a la religión y a la ciencia, la filosofía tiene o debería de tener otra forma de proceder. Como una pri- 
mera aproximación y contestación a las preguntas, ¿para qué enseñar filosofía? y ¿para qué la filosofía?, la respuesta podría sonar así: para mantenernos serenos, críticos y despiertos $^{8}$. Para tener a nuestro lado esa buena dosis de escepticismo necesario para conservar nuestra capacidad racional. En definitiva, pensamos y hacemos filosofía no gracias a los conocimientos que tenemos o a las creencias que, en herencia, hemos recibido; sino, precisamente, y al contrario, a pesar de ellas. Hacemos filosofía, porque lo seguimos necesitando como seres humanos.

Hemos hablado, en el epígrafe anterior, del proceso de racionalización occidental y de la situación en la que deja al saber en general y al saber filosófico en particular. Vamos a profundizar en este asunto, otra vez, pero enfocándolo desde otro prisma.

Vayamos por partes. Todos conocemos la distinción entre lo concreto y lo abstracto. Si pusiésemos sobre la mesa la cuestión del carácter del contenido de la filosofía; es decir, si indagáramos acerca de si el contenido de la filosofía es de tipo concreto o abstracto, no cabe ninguna duda de que todos señalaríamos la segunda opción. Ahora, prestemos atención al siguiente dato: el proceso de racionalización, no solo ha supuesto el triunfo de la racionalidad científico-técnica, sino también la tendencia, cada vez más acusada, hacia la reducción y ulterior supresión de lo abstracto a favor de lo concreto. Si nuestra interpretación es correcta, llegamos a una oposición entre el saber científico, que es un tipo de saber concreto (puesto que enlaza las llamadas ciencias particulares con el ámbito técnico y tecnológico), y el saber filosófico (esto es, la filosofía entendida como reflexión), que es un tipo de saber abstracto.

Hasta aquí, se replicará, nada novedoso. No deja de ser otra forma de abordar la comparación entre la ciencia y la filosofía. De acuerdo, pero volvamos de nuevo a la cuestión que estamos tratando. Porque no nos esta- 
mos limitando a desvelar un rasgo inédito que distingue a la ciencia de la filosofía; pretendemos llegar más lejos. Se trata de asentar y defender la siguiente idea: si el contenido de la filosofía se corresponde con la abstracción y la ciencia se mueve en lo concreto, entonces, el avance de la ciencia, el avance de lo concreto, desplazará al ámbito abstracto, arrinconará a la filosofía y, de seguir esa tendencia, acabará con ella.

Lo que Weber llamó racionalización; lo que los autores de la teoría crítica de la sociedad (Horkheimer, Marcuse, Adorno o Habermas) llamaron el triunfo de la razón instrumental; lo que Heidegger denominó el triunfo del imperio científico-técnico, en fin, todos los planteamientos del denominado pensamiento débil y la posmodernidad, no son otra cosa que el claro síntoma de que la abstracción, asociada a la filosofía, a los grandes sistemas de pensamiento, se bate en retirada. Y, lo que es peor, casi sin posibilidad de rehacerse y lanzar una contraofensiva, un contraataque ${ }^{9}$.

¿Por qué resulta necesaria la defensa de la abstracción? Porque es, en cierta medida, la esencia misma de la filosofía; porque los objetos a los que se dirige el pensar filosófico son universales y no particulares; porque reducir la filosofía a una simple técnica o saber especializado, carece de sentido, puesto que cualquier rama de los saberes científicos y técnicos la superaría; y, además, desvirtuaría su raíz: el pensamiento.

Se nos podría acusar de estar llevando demasiado lejos el papel que desempeña la abstracción, en el sentido en el que nosotros la entendemos, en la filosofía. No obstante, y a modo de réplica ante la posible objeción anterior, basta con tener en cuenta la siguiente consideración. Ya hemos indicado que, en la actualidad, el dominio del conocimiento científico-técnico es abrumador. Decir de algo que está 'científicamente comprobado', no suscita 
ningún género de dudas a nadie; y todo ello, al margen de que, lo 'científicamente comprobado', puede proceder de una investigación en circunstancias muy controladas, con pocos sujetos experimentales, y extrapolando, de manera exagerada, algunos casos posibles por vía inductiva. $\mathrm{Si}$, por el contrario, dejamos caer alguna duda sobre aquello, 'científicamente comprobado'; sobre todo si es una duda de tipo filosófico, se nos dirá, en el mejor de los casos, que estamos hablando de metafísica: es decir, de algo abstracto, vago, carente de significado.

$\mathrm{Y}$, sin embargo, en medio de este discurso de lo concreto, en medio del arrollador avance de la racionalidad científico-técnica, tenemos la sensación de que aquí, algo falla; de que las cosas no van como tienen que ir.

Insistimos. No es un capricho mantener que la filosofía tiene como esencia la abstracción; ni tampoco estamos restando valor al conocimiento científico. Al contrario, creemos que la ciencia es una empresa enorme, grandiosa, extraordinaria, del ser humano. Lo que estamos haciendo es llamar la atención, poner en alerta, ante el avance hipertrofiado de la ciencia, ante la desmesurada credibilidad que la ha convertido, no en un tipo de conocimiento verdadero; sino en la verdad con mayúsculas.

Ese triunfo de lo concreto, personificado en el conocimiento científico, ha traído como consecuencia el que la filosofía se haya venido abajo. Justamente, cuanto más necesaria era su aparición. La filosofía y los 'últimos filósofos', han abdicado de su labor, han rendido sus armas al 'enemigo', han entregado la fortaleza sin luchar. En suma, la filosofía ha eludido su responsabilidad cognoscitiva, ética, e histórica: cognoscitiva porque la abstracción ha cedido frente a lo concreto; ética, porque ha dejado de buscar la verdad y se ha contentado con la verosimilitud; e histórica porque no ha sabido estar a la altura de las circunstancias, porque ha 
sido incapaz de seguir desarrollando su labor en un mundo cada vez más complejo y necesitado de la reflexión.

Ahora, ha llegado el momento de dirigir nuestra atención a dos cuestiones importantes relacionadas con el para qué de la filosofía: ¿se ha cerrado el círculo histórico de la filosofía?, ¿estamos ante el final de la filosofía?

Ocupémonos de la primera. La filosofía ha tenido un comienzo en el tiempo, su andadura se ha iniciado en un determinado periodo histórico, por supuesto. No obstante, ese rasgo, y su propio carácter histórico, no implican el que la filosofía tenga un 'ciclo' que ha de recorrer y concluir. La pretensión de clausurar la filosofía, amparándose en el fin de 'ciclo histórico', es, para expresarlo de otra forma, ininteligible. Parecería que el saber llamado filosofía tiene, desde sus orígenes, no solo un punto de inicio, sino también un final marcado, predeterminado; como si existiera una necesidad inherente al desarrollo de la propia filosofía y que la condujera hacia su irremisible final. Pero, semejante pretensión, deja de lado un pequeño detalle, apenas un acento en este largo discurso, a saber: la filosofía, como cualquier otro saber, no existe sin el sujeto que la hace posible, no es nada sin el ser humano. Por lo tanto, no puede haber clausura ni fin de la filosofía mientras sigan existiendo seres humanos que piensen en términos filosóficos. Y si pensamos en esos términos se debe al hecho de que, aún hoy, nos quedan muchas cuestiones por dilucidar que no están colmadas por la ciencia.

El planteamiento de Heidegger discurre por otros caminos. Su objeto central de reflexión lo encontramos en el Ser y su olvido por parte de la tradición filosófica occidental. A este respecto, escribe el filósofo lo siguiente:

Según la tradición, la filosofía entiende por la pregunta del Ser, la pregunta por el ente en cuanto ente. Es la pregunta de la metafísica. La respuesta a esta pregunta se 
remite siempre a una interpretación del Ser, que se queda en lo impreguntable y prepara el fundamento y suelo para la metafísica. La metafísica no vuelve a su fundamento (Heidegger, 1994: 73).

Ahora bien, Heidegger no se limita a considerar que la pregunta por el Ser haya sido sustituida por la pregunta acerca del ente, en cuanto ente: va más lejos. El olvido del ser conduce a la transformación de la filosofía en metafísica:

La filosofía es metafísica. Esta piensa el ente en su totalidad -mundo, hombre, Dios- con respecto al Ser, a la comunidad del ente en el Ser. La filosofía piensa al ente como ente, en la forma del representar que fundamenta (...) El fundamento -según la impronta de la presenciatiene su carácter fundante como causa óntica de lo real, posibilidad trascendental de la objetividad de los objetos, mediación dialéctica del movimiento del espíritu absoluto, del proceso histórico de producción, como voluntad de poder creadora de valores (Heidegger, 1978: 97) ${ }^{10}$.

Según vemos, la filosofía, que ha ido agotando todas sus posiciones, ha acabado por convertirse solo en metafísica. Dicha conversión, o especialización de la filosofía en metafísica, lleva implícita la tarea de la estructuración de lo real a partir de los entes. Desde este punto de vista, las diversas ciencias derivadas de la filosofía, en su proceso de emancipación, se convierten en una especie de ontologías regionales que actúan en función del campo específico que tengan asignado ${ }^{11}$.

El marco interpretativo de la propuesta de Heidegger resulta sugerente, coherente, profundo e impresionante. Para decirlo, con una sola palabra: impecable. Empero, su filosofía, como la de cualquier otro autor, tiene su punto más vulnerable en su planteamiento; esto es, en los presupuestos de los que parte. 
Dado que, ¿estamos seguros de que la pregunta principal de la filosofía es, como quería Heidegger, la que versa acerca del 'ente' y la 'nada'?: “¿Por qué es el 'ente' y no más bien la 'nada'? es, al parecer, la primera de todas las preguntas" (Heidegger, 1993: 11).

¿Creemos que la filosofía es, básicamente, metafísica y que ésta ejemplifica el olvido del Ser al plantear la cuestión del ente en cuanto ente? ¿Es cierto que la filosofía ha agotado todas las posiciones y que cualquier intento en esa dirección constituiría un simple renacer epigonal?:

El 'final' de la Filosofía es el lugar en el que se reúne la totalidad de su historia en su posibilidad límite. 'Final', como 'acabamiento', se refiere a esa reunión. Bajo formas distintas, el pensamiento de Platón permanece como norma, a lo largo y ancho de toda la Historia de la Filosofía. La metafísica es platonismo. Nietzsche caracteriza su filosofía como platonismo al revés. Con la inversión de la metafísica, realizada ya por Karl Marx, se alcanza la posibilidad límite de la Filosofía. Ésta ha entrado en su estadio final. En la medida en que se intente todavía un pensamiento filosófico, solo se llegará a una variedad de renacimientos epigonales (Heideger, 1978: 98 y 99).

Nos parece que las respuestas a las preguntas anteriores han de ser negativas. Además, creemos que la filosofía es más, mucho más que metafísica. Si el planteamiento de Heidegger es el adecuado, entonces, las conclusiones a las que llega son verdaderas. Pero, precisamente, lo que nos parece cuestionable es su punto de partida. Identificar la filosofía con la metafísica (por muy relevante que haya sido el papel de aquélla en la historia de la filosofía), es identificarla, a fin de cuentas, con una de sus ramas. Sin embargo, la filosofía es un impulso originario que nace de la capacidad humana de pensar, de interrogarnos sobre todo aquello que nos rodea: un intento de elevar nuestra 
vida por encima del círculo de lo material, de lo inmanente, hacia lo trascendente.

En definitiva, no compartimos ni los supuestos ni las conclusiones a las que llega Heidegger; pero sí, su extraordinario esfuerzo por intentar pensar más allá de los márgenes del pensar mismo. Al igual que Nietzsche, Heidegger intenta encontrar nuevas categorías para pensar lo que, todavía, no se puede pensar; que en su caso es, "aquello que hace posible el que algo aparezca o se muestre, lo abierto, la Lichtung del Ser"12:

Todo pensar bajo la forma de Filosofía que, expresamente o no, sigue la llamada "a la cosa misma" se confía ya, en su marcha, con su método, a la libertad de la Lichtung. Sin embargo, la Filosofía no sabe nada de la Lichtung. Es verdad que habla de la luz de la razón, pero no se preocupa por la Lichtung del Ser (Heidegger, 1978: 110).

\section{Conclusión}

Tiempo es ya de concluir. A lo largo del presente artículo se han abordado dos cuestiones de capital importancia para el autor. De una parte, la que se refiere a la enseñanza de la filosofía, tanto en los niveles de la enseñanza secundaria como en el ámbito universitario. Aquí, el eje central sobre el que giró toda la reflexión fue el referido al tipo de enseñanza; es decir, al de los contenidos y el de su profundidad a la hora de exponerlos. Contenidos que se veían fuertemente marcados por el fenómeno del creciente aumento del conocimiento en general, que dejaba atrás, en cierta medida, al contenido de la misma filosofía.

En relación con lo anterior, se discutió, también, si dichos contenidos debían de ser preparatorios o propedéuticos; esto es, a modo de introducción de algunos cono- 
cimientos previos (de sociología, psicología, antropología, ética, etcétera) o debían dirigirse hacia la 'Historia de la Filosofía' y los autores (todo ello, tomando como referencia la interpretación de los textos). En este último caso, se planteó la cuestión de si la historia de la filosofía era adecuada o no a lo que los alumnos debían de aprender hoy día sobre la misma filosofía. La conclusión que se extrajo de este primer epígrafe fue que la enseñanza de la filosofía, ante el creciente avance del conocimiento y la imposibilidad de poder abarcarlo todo, debía gravitar entre la propedéutica y la historia de la filosofía; dando un peso mayor a los temas que se acercan mucho más al momento actual. Todo ello, en medio de una constante revitalización y puesta al día, en la medida de lo posible, de lo que ha sido, es y debe ser, la filosofía.

Por otra parte, la cuestión del sentido de la filosofía, el para qué, se trató en el segundo epígrafe del artículo. Las conclusiones principales que se extrajeron de este apartado, vinieron precedidas de una reflexión acerca de la necesidad de la pregunta por el sentido mismo de la filosofía. Dicha pregunta nos llevó de forma directa a la conclusión principal de este apartado: la definición de la filosofía como un saber de tipo abstracto que ha cedido casi todo el terreno frente al avance de lo concreto personificado en el saber científico-técnico. En este contexto, perder lo 'abstracto' frente a lo 'concreto', simboliza perder el pensamiento frente a la acción instrumental, perder la racionalidad teórico-práctica (entendiendo práctica, en sentido moral), frente a la racionalidad científico-técnica. Expresado de otra forma, arrinconar y eliminar el ámbito de lo trascendente, de lo que va más allá de lo cotidiano; a favor de lo concreto, de lo cotidiano, de lo real en sentido material. En síntesis: eliminar la trascendencia frente a la inmanencia. Otro aspecto importante analizado igualmente en este segundo epígrafe, fue el relativo a la 'clausu- 
ra' y el 'final' de la filosofía. Se prestó especial atención al planteamiento de Heidegger.

La conclusión principal que se obtuvo, apuntó al rechazo de ambas posiciones: no hay clausura ni final de la filosofía; por distintas razones que allí fueron explicadas.

Debemos volver a las fuentes originarias del pensamiento filosófico, pues solo cuando la filosofía recupere la fuerza y la confianza en sí misma; solo cuando el pensar vuelva a resurgir con vigor, se podrá prestar a la humanidad el servicio que le debe la filosofía. ¿Cómo se logrará esto? Resulta difícil de decir; pero necesitamos que quienes, en el futuro, se ocupen de ello, retomen el pulso de nuestra disciplina y salgan a la luz. En un mundo donde cada vez es más rara la experiencia del pensar (en sentido pleno, auténtico), en donde lo real va cediendo terreno a lo virtual, donde se da más importancia a las redes sociales que a las redes neuronales (las de nuestro propio cerebro, las que hacen posible que cada uno de nosotros piense por sí mismo y tenga conciencia de lo que hace), entonces, en ese mundo, en nuestro mundo, sigue siendo necesaria, aún, la filosofía.

El futuro deberá mostrar si las conclusiones de este artículo, que ya finaliza, son correctas o no. En cualquier caso, los lectores que hayan tenido la paciencia de acompañarnos hasta aquí, quedan invitados a una reflexión sobre todo ello.

\section{Notas}

1 Obsérvese que tomamos filosofía como sinónimo de filosofía occidental. No tratamos de situarnos en una posición etnocéntrica, dando primacía a la cultura occidental sobre el resto de las culturas. Lo que sucede es que la filosofía occidental tiene unas características muy peculiares que no encontramos en otras variantes filosóficas procedentes de China o la India, por citar algunos ejemplos. Ade- 
más, es esta concepción de la filosofía occidental sobre la que gira nuestro artículo.

2 Se entiende aquí, por 'filosofía académica', la que se imparte en los centros de enseñanza, ya sean de secundaria o universitarios, por contraposición a la 'filosofía profesional', realizada por los filósofos y que, en principio, no persigue ningún fin pedagógico sino la reflexión sobre la realidad.

3 Al hablar de 'planes de estudio' nos estamos refiriendo, en especial, al caso más cercano para nosotros; es decir, el de España. Junto a las facultades de Filosofía, en España, la filosofía se imparte también en la enseñanza secundaria. Concretamente, en los cursos de $1^{\circ}$ y $2^{\circ} \mathrm{de}$ bachillerato (esto es, en los dos cursos inmediatamente anteriores al ingreso en la Universidad). El curso de $1^{\circ}$ es una introducción, a modo de propedéutica, a la filosofía: se abordan nociones de lógica, sociología, psicología, teoría del conocimiento, ética, etcétera. El curso de $2^{\circ}$ se ocupa de la Historia de la Filosofía, a través de una selección de autores; entre ellos, Platón, Aristóteles, San Agustín, Santo Tomás, Ockham, Descartes, Hume, Kant, Hegel, Marx, Nietzsche, Bertrand Russell, Ortega y Gasset, Heidegger y Sartre, principalmente. Por supuesto, somos conscientes de que, en otros países, esta situación puede ser diferente y por ello, lo que se indica en nuestro artículo, debería ser adaptado, si fuera posible, a lo que sucede en cada país.

4 Weber se ocupa de la racionalización occidental en diversas partes de sus obras y la considera un sello particular de la cultura de occidente. Así, en La ética protestante y el espíritu del capitalismo, afirma: Es evidente que, en todos estos casos, se trata de un "racionalismo" específico y peculiar de la civilización occidental. Ahora bien, bajo estas dos palabras pueden entenderse cosas harto diversas, como habrá ocasión de poner de relieve en las páginas siguientes. Hay, por ejemplo, "racionalizaciones" de la contemplación mística (es decir, de una actividad que, vista desde otras esferas vitales, constituye algo específicamente "irracional”), como las hay de la economía, de la técnica, del trabajo científico, de la educación, de la guerra, de la justicia y de la administración. Además, cada una de estas esferas puede ser "racionalizada" desde distintos puntos de vista, y lo que desde uno se considera "racional" parece "irracional" desde otro. Procesos de racionalización, pues, se han realizado en todas partes y en todas las esferas de la vida. Lo característico de su diferenciación histórica y cultural es precisamente cuáles de estas esferas, y desde 
que punto de vista, fueron racionalizadas en cada momento (Weber, 1977: 17).

5 Por escepticismo, no nos referimos aquí a la escuela filosófica que lleva ese nombre, ni tampoco a la doctrina de la epojé o suspensión del juicio. La utilizamos más bien en el sentido de precaución: se trata de evitar, pues, la precipitación en el juicio, sopesar las palabras antes de pronunciarlas, analizar las consecuencias de nuestros actos antes de llevarlos a cabo. En definitiva, escepticismo, encierra para nosotros, la prudencia, la reflexión y el sentido común.

6 El lema se encuentra, como es sabido, al comienzo del escrito. Respuesta a la pregunta: ¿qué es la Ilustración?

7 Cosmos entendido como Universo o totalidad de cuánto existe. Por supuesto, hay en dicha palabra una evocación del título de la conocida obra de Max Scheler, El puesto del hombre en el cosmos.

8 Despiertos supone una reminiscencia de la metáfora que utiliza Heráclito al hablar del Logos y la actitud de los hombres ante este principio supremo: "Para los despiertos hay un mundo único y común, mientras que cada uno de los que duermen se vuelve hacia uno particular" (Heráclito, 1978: 390-391).

9 Al proceso de racionalización occidental de Max Weber ya nos hemos referido anteriormente. La teoría crítica de la sociedad está asociada a la denominada Escuela de Frankfurt, a la que pertenecen pensadores como los citados; si bien es cierto que, el último de los citados, Habermas, difiere en ciertos aspectos de los restantes y desarrolla su propio programa filosófico, tomando como eje central la teoría de la acción comunicativa. Sobre Heidegger hablaremos más adelante al abordar las cuestiones del final de la filosofía. Aunque, y a modo de anticipo, hay que decir que este autor, a pesar de reconocer el impacto del conocimiento científico-técnico sobre el saber en general y la filosofía en particular, no considera, como nosotros, que la causa del final de la filosofía sea el avance de lo concreto: sino el olvido del Ser, llevado a cabo por la metafísica y la conversión de la filosofía, precisamente, solo en eso, es decir, en metafísica. Por último, los autores englobados bajo la denominación de pensamiento débil y posmodernidad, no han dejado de insistir en la consideración del conocimiento como una colección de historias o relatos literarios, productos de la incapacidad de la razón para fundamentar un discurso sólido, bien estructurado, fuerte. De ahí procede el adjetivo 'débil'; adjetivo que, incluso, les parece deseable ante el dogmatismo y los derroteros a los que nos han conducido, suponen ellos, el pensamiento fuerte. 
10 En el texto, Heidegger se refiere, por este orden y sin citarlos, a Platón, Kant, Hegel, Marx y Nietzsche.

11 Desde aquí y hasta el final de este epígrafe (esto es, justo antes del apartado dedicado a las conclusiones), se recogen algunas ideas y textos que ya habían sido expuestos en la tesis doctoral del autor de este artículo; aunque, en el caso de Heidegger, se estableció la comparación con Nietzsche, teniendo presente el objetivo de aquel trabajo académico que no era otro que el tema del nihilismo (La referencia concreta es: Sánchez Álvarez, 1998: 249-73).

12 Uno de los puntos más complejos de la exposición de Heidegger, y, al mismo tiempo, más controvertidos, es el que apunta a la relación entre el Ser y el hombre. Atendamos al autor: "La esencia humana consiste más bien en que siempre así como así se mantiene y vive en la donación. Decimos siempre del "Ser mismo" demasiado poco, si al decir "el Ser", omitimos la presencia para la esencia humana, y con ello desconocemos que esa esencia misma forma parte de "el Ser". Decimos también siempre demasiado poco del hombre, si al decir "el Ser" (no el ser humano), ponemos al hombre para sí, y lo así puesto lo ponemos entonces otra vez en relación con el "Ser". Pero también decimos demasiado, si pensamos en el Ser como lo omniabarcante y con ello representamos al hombre solo como un ente especial entre otros (plantas, animales) y a ambos los ponemos en relación... (Heidegger, 1994: 103).

Como vemos, la dificultad estriba en determinar el grado de la relación entre el hombre y el Ser. Uno y otro están, sin duda, relacionados. Pero, ¿de qué forma? Porque, descartando que el Ser deba considerarse como un concepto omniabarcador, entonces, lo único que nos queda es suponer que son dos realidades distintas: ahora bien, esta última afirmación tampoco concuerda con lo que dice Heidegger en el resto de la obra citada. Al autor no le resulta fácil especificar esa relación. A nosotros nos parece que, a pesar de los esfuerzos de Heidegger, el concepto de Ser acaba por subsumir, de una forma u otra, a la esencia humana, al hombre. Creemos, que el Ser, al modo de Heidegger, termina por ocultar y olvidar al hombre. Si nuestras suposiciones son ciertas, se produciría la curiosa paradoja de la apertura hacia una nueva forma de pensar, que sería un pensar de nadie: dado que, la Lichtung del Ser, no se identifica con el hombre, con el ser humano.

\section{Bibliografía}

\section{Textos}

\section{Heidegger, Martín}

1978 "El final de la filosofía y la tarea del pensar”, en: ¿Qué es filosofía? Madrid: Narcea. 
1993 Introducción a la metafísica. Barcelona: Gedisa

1994 "Hacia la pregunta del ser", en: Acerca del nihilismo. Barcelona: Paidós.

Kant, Inmanuel

1995 Crítica de la razón pura. Madrid: Alfaguara.

Ortega y Gasset, José

1972 ¿Qué es filosofía? Madrid: Revista de Occidente.

Weber, Max

1977 La ética protestante y el espíritu del capitalismo. Barcelona: Ed. Península.

1984 "La ciencia como vocación", en: El político y el científico. Madrid: Alianza Editorial.

\section{Fragmentos sobre autores y artículos}

Albiac, Gabriel

2009 El resto es barbarie. Madrid: diario ABC.

Heráclito

2000 Contenido en Los filósofos presocráticos. Volumen I. Madrid: Editorial Gredos.

\section{Tesis doctorales}

Sánchez Álvarez, Vicente

1998 Origen y sentido del nihilismo en la filosofía de Nietzsche. Servicio de Publicaciones de la Universidad Complutense de Madrid, Facultad de Filosofía, sección tesis doctorales. 